\title{
Heavy Metals in Air Emission and Assessment of Human Toxicity Footprint
}

\author{
Junbeum Kim ${ }^{1,2+\oplus}$ \\ ${ }^{1}$ CREIDD Research Center on Environmental Studies \& Sustainability, Department of Humanities, Environment \& Information \\ Technology, University of Technology of Troyes, 12 rue Marie Curie B.P. 2060, 10010 Troyes Cedex, FRANCE \\ ${ }^{2}$ Europe Environment and Energy Association
}

(Received July 14, 2021; Revised September 29, 2021; Accepted September 29, 2021)

Objective: The purpose of this study is to propose the concept of the human toxicity (human cancer and non-cancer) footprint ( $\mu \mathrm{g} \mathrm{1,4}$ DCB (Dichlorobenzene) eqv. $/ \mathrm{m}^{3}$ ) using heavy metal concentration data in the air in Provincial and Metropolitan City governments. In addition, the final goal is to assess and compare the human carcinogenic toxicity footprint in Provincial and Metropolitan City Governments from 1991 to 2019.

Method: To calculate the human carcinogenic toxicity footprint using heavy metal concentration in Provincial and Metropolitan City Governments, the ReCiPe 2016 life cycle impact assessment method in life cycle assessment (LCA) was used. For the human carcinogenic toxicity footprint calculation, the heavy metal concentration data in Provincial and Metropolitan City Governments are multiplied by the characterization factors of each heavy metal such as $\mathrm{Pb}, \mathrm{Cd}, \mathrm{Cr}, \mathrm{Ni}$, and $\mathrm{As}(\mathrm{Cu}, \mathrm{Mn}, \mathrm{Fe}, \mathrm{Al}, \mathrm{Ca}$, and $\mathrm{Mg}$ are not included in the air monitoring data) data $\left(\mu \mathrm{g} / \mathrm{m}^{3}\right)$. The unit of human carcinogenic toxicity footprint is shown in $\mu \mathrm{g} 1,4 \mathrm{DCB}$ eqv. value.

Results and Discussion: The results show that the heavy metal concentrations in Provincial and Metropolitan City governments were decreased significantly from 1991 to 2019 . In the case of $\mathrm{Pb}$, Incheon was decreased by about 2,124\% (from $0.427 \mu \mathrm{g} / \mathrm{m}^{3}$ to $0.0192 \mu \mathrm{g} / \mathrm{m}^{3}$ ), and Busan was decreased by about $1,250 \%$ (from 0.2471 $\mu \mathrm{g} / \mathrm{m}^{3}$ to $0.0183 \mu \mathrm{g} / \mathrm{m}^{3}$ ). In addition, in Cd's case, Gwangju decreased by about $1,550 \%$ (from $0.0033 \mu \mathrm{g} / \mathrm{m}^{3}$ to $0.0002 \mu \mathrm{g} / \mathrm{m}^{3}$ ), and Incheon was decreased by about $1,071 \%$ (from $0.0082 \mu \mathrm{g} / \mathrm{m}^{3}$ to $0.0007 \mu \mathrm{g} / \mathrm{m}^{3}$ ). The results of human carcinogenic toxicity footprint in 1991 (early stage), 2005 (middle-stage), and 2019 (current) show that the average of human carcinogenic toxicity footprint was $8,478 \mu \mathrm{g} 1,4 \mathrm{DCB}$ eqv. in $1991,5,545 \mu \mathrm{g} 1,4 \mathrm{DCB}$ eqv. in 2005 (about 53\% decreased from 1991), and 1,997 $\mu \mathrm{g}$ 1,4 DCB eqv. in 2019 (about 178\% decreased from 2005). In 2019, the human carcinogenic toxicity footprint results showed that Gyeongbuk had the highest value of 5,184 $\mu \mathrm{g}$ 1,4 DCB eqv. followed by Busan 3,929 $\mu \mathrm{g}$ 1,4 DCB eqv., Gyeongi 3,305 $\mu \mathrm{g}$ 1,4 DCB eqv., Seoul 2,184 $\mu \mathrm{g}$ 1,4 DCB eqv., Gwangwon 2,011 $\mu \mathrm{g}$ 1,4 DCB eqv. One of the reasons for the highest human carcinogenic toxicity footprint is the concentration of $\mathrm{Cr}$ and $\mathrm{As}$, which have very high characterization factors.

Conclusions: In this study, the human carcinogenic toxicity footprint using a heavy metal concentration in Provincial and Metropolitan City governments was proposed and calculated. Even though the heavy metal concentrations were decreasing, the number of measuring stations should be increased in each Provincial and Metropolitan City Government to improve the data quality and reduce the human carcinogenic toxicity impact by heavy metals.

Keywords : air emission, toxicity footprint, human carcinogenic, heavy metals, life cycle impact assessment

The Korean text of this paper can be translated into multiple languages on the website of http://jksee.or.kr through Google Translator.

\section{Corresponding author}

E-mail: junbeum.kim@utt.fr; junbeum.kim@gmail.com

Tel: +33-03-2571-8006 Fax: +33-03-2571-7698

(c) 2021, Korean Society of Environmental Engineers

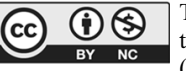

This is an Open Access article distributed under the terms of the Creative Commons Attribution Non-Commercial License (http://creativecommons.org/licenses/by-nc/4.0/) which permits unrestricted non-commercial use, distribution, and reproduction in any medium, provided the original work is properly cited. 


\section{연구논문}

\section{국내 대기오염 중금속물질과 인체 독성발자국 평가}

\section{김준범 ${ }^{1,2+}$}

${ }^{1}$ 프랑스 트루아공대, 환경정보기술학과, 환경 및 지속가능성연구센터

2유럽환경에너지협회

목적: 본 연구의 목적은 국내 지자체 대기 중 중금속 농도자료를 바탕으로 산정되어질 수 있는 인체 독성발자국 (인체 발암성 및 비발암성, $\mu \mathrm{g} 1,4 \mathrm{DCB}$ eqv. $/ \mathrm{m}^{3}$ )의 개념을 제시하고 1991년부터 2019년까지 국내 지자체별로 분석 하여 비교평가 하는 것이다.

방법: 국내 지자체에서 대기 중 중금속 자료를 바탕으로 인체 독성발자국을 산정하기 위해서 전과정 영향평가 방 법에서 ReCiPe 2016 영향평가방법을 사용하였다. 인체 독성발자국은 대기중 중금속 자료(예를 들면, $\mathrm{Pb}, \mathrm{Cd}, \mathrm{Cr}$, $\mathrm{Ni}, \mathrm{As}$ (대기 모니터링 자료에서 $\mathrm{Cu}, \mathrm{Mn}, \mathrm{Fe}, \mathrm{Al}, \mathrm{Ca}, \mathrm{Mg}$ 은 제외 $\left.\left(\mu \mathrm{g} / \mathrm{m}^{3}\right)\right)$ 와 각각의 중금속 특성화계수를 활용하여 산정되어질 수 있다. 인체 독성발자국의 단위는 $\mu \mathrm{g} 1,4 \mathrm{DCB}$ eqv.이다.

연구결과 및 토론 : 국내 지자체에서의 대기 중 중금속 농도는 1991년부터 2019년까지 지속적으로 감소되어져왔다. 납 $(\mathrm{Pb})$ 의 경우에는 인천과 부산에서는 각각 $2,124 \%\left(0.427 \mu \mathrm{g} / \mathrm{m}^{3}\right.$ 에서 $\left.0.0192 \mu \mathrm{g} / \mathrm{m}^{3}\right)$ 와 $1,250 \%\left(0.2471 \mu \mathrm{g} / \mathrm{m}^{3}\right.$ 에서 $\left.0.0183 \mu \mathrm{g} / \mathrm{m}^{3}\right)$ 로 상당히 많은 양이 저감되어진 것을 볼 수 있었다. 그리고 카드뮴 $(\mathrm{Cd})$ 의 경우에도 광주와 인천에서 각각 $1,550 \%\left(0.0033 \mu \mathrm{g} / \mathrm{m}^{3}\right.$ 에서 $\left.0.0002 \mu \mathrm{g} / \mathrm{m}^{3}\right)$ 와 $1,071 \%\left(0.0082 \mu \mathrm{g} / \mathrm{m}^{3}\right.$ 에서 $\left.0.0007 \mu \mathrm{g} / \mathrm{m}^{3}\right)$ 로 상당히 많은 양이 저 감되어진 것을 볼 수 있었다. 국내 지자체별 인체 독성발자국 결과를 살펴보면, 1991 년(초기)에는 평균 $8,478 \mu \mathrm{g}$ 1,4 DCB eqv., 2005년(중기)은 평균 5,545 $\mu \mathrm{g} 1,4 \mathrm{DCB}$ eqv.으로 1991년에 비해서 53\% 저감되었다. 2019년도는 평 균 $1,997 \mu \mathrm{g} 1,4 \mathrm{DCB}$ eqv.으로 2005년도 결과에 비해서 $178 \%$ 로 상당히 많이 저감이 되었다. 2019년 지자체별 인 체 독성발자국 결과에서는 경북이 $5,184 \mu \mathrm{g} 1,4 \mathrm{DCB}$ eqv.으로 가장 높은 수치를 나타내었으며, 부산 3,929 $\mu \mathrm{g} 1,4$ $\mathrm{DCB}$ eqv., 경기 3,305 $\mu \mathrm{g} 1,4 \mathrm{DCB}$ eqv., 서울 2,184 $\mu \mathrm{g} 1,4 \mathrm{DCB}$ eqv., 강원 2,011 $\mu \mathrm{g} 1,4 \mathrm{DCB}$ eqv.으로 그 뒤를 이었다. 높은 인체 독성발자국 수치를 나타낸 주요 원인 중 하나는 대기오염 중금속 중에서 특성화값이 높은 크롬 과 비소의 양이 높기 때문이라고 할 수 있다.

결론 : 본 연구에서는 국내 지자체에서의 대기 중 중금속자료를 기초로 하여 인체 독성발자국을 제시하고 산정하였 다. 계속적으로 대기 중 중금속량은 저감하고 있지만 지자체별로 더 많은 측정소 설치가 요구되며, 이를 통해서 자 료의 질 향상과 인체 독성발자국 수치를 낮추는데 노력을 해야 될 것이다.

주제어: 대기오염, 독성발자국, 인체 발암성, 중금속, 국내 지자체, 전과정 영향평가

\section{1. 서론}

도시화 및 산업화로 인해서 발생되어진 환경오염 및 대기오 염과 관련된 사회적 문제들이 계속적인 관심사로 대두되어지 고 있다. 지난 30 년간 국내에서 발생되어진 중금속 및 대기오 염물질들은 지속적으로 줄어들고 있으며, 이로 인한 환경적 영향들도 많은 연구와 저감정책으로 인해서 줄어들고 있다. ${ }^{1)}$ 세계보건기구(WHO)는 대기오염을 "대기 중에 인위적으로 배출된 오염물질이 한 가지 또는 그 이상 존재하여 오염물질 의 양, 농도 및 지속시간이 어떤 지역의 불특정 다수인에게 불쾌감을 일으키거나 해당 지역에 공중보건상 위해를 끼치고,
인간이나 동-식물의 활동에 해를 주어 생활과 재산을 향유할 정당한 권리를 방해받는 상태"로 정의하고 있다. ${ }^{2)}$ 국가미세먼 지 정보센터 ${ }^{1)}$ 에서는 정기적으로 대기오염물질 중에서 $\mathrm{CO}$, $\mathrm{NOx}, \mathrm{SOx}, \mathrm{TSP}, \mathrm{PM} 10, \mathrm{PM} 2.5, \mathrm{VOC}$ 등의 자료들을 구축하여 결과들을 공지하고 있으며, 해마다 국립환경과학원에서는 대 기환경연보를 발간하여 대기오염, 대기오염측정망, 측정방법, 지역별 대기오염도 현황 등에 대한 정보들을 자세히 제공하고 있다. ${ }^{3)}$

도시 및 산업단지 근교에서 측정 및 대기 및 토양오염 모니 터링되고 있는 대기오염물질과 미량의 중금속 물질들은 호흡 기질환과 같은 환경성 질환을 일으킬 수 있으며, 미세먼지에 
포함되어 있거나 부유하면서 인체 호흡기로 흡입 및 축적이 되어, 인간의 발암과 독성에 영향을 미칠 수 있다.-7) 또한, 대기오염물질과 암 발생 간의 상관관계를 평가한 연구가 진행 이 되었다. 환경부 대기오염 통계자료와 보건복지부 암발생 통계자료를 바탕으로 대기오염 중 발암물질에 대해서 US $\mathrm{EPA}$ 위해성 평가 방법을 사용하여 발암물질의 호흡노출량과 암발생간의 상관성분석을 실시하였다. ${ }^{8)} \mathrm{Lee}^{9)}$ 연구는 대기 중 미세먼지를 포집하여 포집된 시료를 입경별로 중금속을 분석 하여 계절 및 교통량의 차이, 연무 현상의 유무에 따른 차이를 분석하였으며, 입자의 호흡기 내 침착 가능성을 감안하여 입경 별로 인체 위해성에 대한 비교평가를 수행하였다. Park 외 ${ }^{10)}$ 연구는 국내 대기 중의 미세먼지 $\left(\mathrm{PM}_{10}\right.$ 과 $\left.\mathrm{PM}_{2.5}\right)$ 의 분포와 미 세먼지 속에 포함되어져 있는 중금속 $(\mathrm{Cr}, \mathrm{Mn}, \mathrm{Zn}, \mathrm{As}, \mathrm{Cd}, \mathrm{Pb})$ 성분 및 함량을 분석하여 중금속을 흡입하였을 경우의 인체위 해성을 평가하였으며, 각 중금속 성분이 호흡기를 통해 흡수 되어 순환함으로써 심장세포에 야기될 수 있는 독성을 실험적 연구를 통해 비교 및 평가연구를 수행하였다. 이와 같이 도시 대기 중의 대기오염물질 및 중금속은 화석연료의 고온의 연료 연소과정에서 배출되어지며, 교통수단, 소각, 보일러 및 공장 에서의 연료소비 등으로 인한 인위적인 배출원에서 배출되어 진다. 따라서, 미세입자 및 극미세입자 내 중금속의 저감과 지속적인 관리는 상당히 중요하다고 할 수 있다.

앞서 서술하였듯이 이와 관련된 연구들이 많이 진행되고 있 지만, 국내 지자체별 대기 중의 중금속과 인체독성평가 및 발 자국 분석에 관한 연구는 많이 수행되어지고 있지 않다. 다시 말하면, 지자체별 각각의 대기 중의 중금속량을 가지고 높고 낮음을 평가 및 비교는 가능할 수 있지만, 인체 독성평가 발자 국지표로 한 연구분석은 전무하다. 또한, 전과정평가의 영향 평가방법에서는 여러 영향범주들에 대해서 오염물질로 인한 영향들을 정규화 및 수치화하고 있으며, 제품생산(원료취득 및 제품생산 프로세스)에서 발생되는 오염물질들을 바탕으로 각 물질들의 특성화계수를 활용하여 영향범주별로 영향들을 산정해 오고 있다. 전과정 영향평가에서 중금속으로 인한 독 성지표 산정과 관련되어서는 이미 구축된 개념 및 방법이며, 제품이나 서비스에 적용한 다른 선행 연구를 통해 적용성이 검증되어왔다고 할 수 있다. 본 연구에서는 제품에 적용되어 온 독성지표를 다른 시스템(대기오염 자료)에 적용하여 그 평 가 결과에 대한 세부 분석을 통해서 그 의미를 규명하는데 큰 의미가 있다고 할 수 있다.

이에 본 연구의 목적으로 대기 중 중금속 양을 바탕으로 인 체 독성발자국에 대한 개념 적립과 평가 방법을 제시하고 있 다. 본 연구에서는 인체 독성발자국 평가 및 적용부분에서 제 품과 서비스가 아닌 국내 지자체를 대상으로 적용하는 것으로 1991년부터 2019년까지 연도별 및 지자체별 대기 중 중금속 오염도 자료(Lead, Cadmium, Chromium, Copper, Manganese, Iron, Nickel)를 바탕으로 국내 지자체별로 인체 독성발자국을
비교분석하고자 하였다.

\section{2. 연구자료 및 방법}

\section{1. 연구자료}

국립환경과학원 대기환경연보 ${ }^{3)}$ 에 따르면 현재 환경부 및 국내지자체에서 운영하고 있는 “총 11 개 종류의 측정망(도시 대기, 도로변대기, 산성강하물, 국가배경농도, 교외대기, 대기 중금속, 유해대기물질, 광화학대기오염물질, 지구대기, $\mathrm{PM}_{2.5}$ 성분, 대기오염집중)은 전국 총 676개소"가 있다.

대기환경연보에서 제공하고 있는 1991년부터 2019년까지 의 시도별 대기 중 중금속 납 $(\mathrm{Pb})$, 카드뮴 $(\mathrm{Cd})$, 크롬 $(\mathrm{Cr})$, 니켈 $(\mathrm{Ni})$, 비소(As) 오염도자료 $\left(\mu \mathrm{g} / \mathrm{m}^{3}\right)$ 를 평가에 활용하였다. 대기 환경연보에서 제공되어지고 있는 구리 $(\mathrm{Cu})$, 망간 $(\mathrm{Mn})$, 철 ( $\mathrm{Fe}), \mathrm{Al}$ (알루미늄), $\mathrm{Ca}$ (칼슘), $\mathrm{Mg}$ (마그네슘)은 산정에서 제외 하였음). 대기모니터링 항목에서 납 $(\mathrm{Pb})$, 카드뮴 $(\mathrm{Cd})$, 크롬 $(\mathrm{Cr})$, 구리 $(\mathrm{Cu})$, 망간 $(\mathrm{Mn})$, 철 $(\mathrm{Fe})$, 니켈 $(\mathrm{Ni})$ 물질은 1991년부 터 2019년까지 계속적으로 측정을 해오고 있지만, 비소(As)는 2011 년부터, 베릴륨(Be), 알루미늄( $\mathrm{Al})$, 칼슘 $(\mathrm{Ca})$, 마그네슘 $(\mathrm{Mg})$ 은 2017년부터 측정 및 분석을 해오고 있다. 또한, 지역 별로 살펴보면, 경기도의 경우 1997년부터, 충북과 전북의 경 우는 2005년부터, 충남의 경우에는 2009년부터, 그리고 경남 의 경우는 2013년부터 대기 중 주요 금속 및 중금속량을 측정 하기 시작하였다. Table1에서는 한 예로, 2019년 지역별 대기 중 금속 및 중금속농도 $\left(\mu \mathrm{g} / \mathrm{m}^{3}\right)$ 을 보여주고 있다.

\section{2. 연구방법}

앞에서 한 예로 보여준 Table 1과 같이 년도별 및 지역별 대기 중 금속 및 중금속 자료를 가지고는 Fig. 1 에서와 같이 2019년 자료를 분석하여 보여줄 수 있다. 납 $(\mathrm{Pb})$ 의 경우에는 경기도, 경북, 충남 순으로 높은 농도를 보여지고 있으며, 카 드뮴 $(\mathrm{Cd})$ 은 경기, 대구, 울산 순으로, 크롬 $(\mathrm{Cr})$ 은 경북, 부산, 경기 순으로, 그리고 구리 $(\mathrm{Cu})$ 는 경기, 서울, 부산 순으로 높음 을 알 수 있다. 이와 같은 대기 중 중금속 농도 자료를 가지고 는 년도별로 $\mathrm{A}$ 지역에서는 납 $(\mathrm{Pb})$ 과 카드뮴 $(\mathrm{Cd})$ 이 높은 지역 이고, $\mathrm{B}$ 지역에는 크롬 $(\mathrm{Cr})$ 과 구리 $(\mathrm{Cu})$ 가 높은 지역으로만 결 과들을 보여줄 수 있기 때문에 전체 다양한 금속 및 중금속 자료 및 결과를 가지고는 종합적인 평가와 분석의 한계가 있 다고 할 수 있다.

이와 같은 연구배경 및 문제부분을 바탕으로 본 연구에서 는 대기오염 중금속으로 인한 인체 독성발자국(Human Toxicity Footprint) 평가 방법을 제시하고 국내 지자체별로 비 교분석을 하고자 한다. 인체 독성발자국 평가를 위해서는 우 선 전과정 평가(life cycle assessment)과정에서 수행되어지는 전과정 영향평가(life cycle impact assessment) 방법들을 활용 할 수 있으며, 많이 사용되고 방법론 중에서 ReCiPe 2016 V.1.1 ${ }^{11)}$ 
Table 1. Metal and heavy metal concentration in Provincial and Metropolitan City governments (2019) (Source: Annual report of air quality in Korea, $2020^{3)}$ )

\begin{tabular}{cccccccccccccc} 
& $\mathrm{Pb}$ & $\mathrm{Cd}$ & $\mathrm{Cr}$ & $\mathrm{Cu}$ & $\mathrm{Mn}$ & $\mathrm{Fe}$ & $\mathrm{Ni}$ & $\mathrm{As}$ & $\mathrm{Be}$ & $\mathrm{Al}$ & $\mathrm{Ca}$ & $\mathrm{Mg}$ \\
Seoul & 0.0258 & 0.0007 & 0.0031 & 0.0243 & 0.0211 & 0.6929 & 0.0025 & 0.0054 & N.D. & 0.2588 & 0.5986 & 0.1638 \\
\hline Busan & 0.0183 & 0.0007 & 0.0057 & 0.0177 & 0.0349 & 0.6537 & 0.0049 & 0.0058 & N.D. & 0.1901 & 0.4814 & 0.1819 \\
\hline Daegu & 0.0236 & 0.0011 & 0.0028 & 0.0145 & 0.0193 & 0.5547 & 0.0019 & 0.0031 & N.D. & 0.2046 & 0.5122 & 0.1821 \\
\hline Incheon & 0.0192 & 0.0007 & 0.0027 & 0.0158 & 0.0187 & 0.4742 & 0.0032 & 0.0034 & N.D. & 0.2192 & 0.3553 & 0.1138 \\
\hline Gwangju & 0.0106 & 0.0002 & 0.0006 & 0.0077 & 0.0156 & 0.3535 & 0.0007 & 0.0019 & N.D. & 0.1749 & 0.5419 & 0.1632 \\
\hline Daejeon & 0.0162 & 0.0004 & 0.0015 & 0.0123 & 0.0206 & 0.5157 & 0.0022 & 0.0024 & N.D. & 0.2527 & 0.5080 & 0.1686 \\
\hline Ulsan & 0.0187 & 0.0010 & 0.0010 & 0.0138 & 0.0225 & 0.5299 & 0.0032 & 0.0041 & N.D. & 0.2452 & 0.5392 & 0.1965 \\
\hline Gyeongi & 0.0337 & 0.0013 & 0.0048 & 0.0396 & 0.0290 & 0.6375 & 0.0061 & 0.0054 & N.D. & 0.5702 & 0.4762 & 0.1944 \\
\hline Gangwon & 0.0161 & 0.0006 & 0.0026 & 0.0098 & 0.0297 & 0.5013 & 0.0014 & 0.0036 & N.D. & 0.2598 & 0.5205 & 0.1599 \\
\hline Chungbuk & 0.0156 & 0.0008 & 0.0022 & 0.0156 & 0.0204 & 0.5145 & 0.0114 & 0.0029 & N.D. & 0.2685 & 1.3035 & 0.2126 \\
\hline Chungnam & 0.0276 & 0.0003 & 0.0024 & 0.0133 & 0.0460 & 1.8485 & 0.0027 & 0.0036 & N.D. & 0.8075 & 1.1669 & 0.2981 \\
\hline Jeonbuk & 0.0154 & 0.0006 & 0.0019 & 0.0066 & 0.0132 & 0.3501 & 0.0011 & 0.0024 & N.D. & 0.2369 & 0.5303 & 0.1671 \\
\hline Jeonnam & 0.0087 & 0.0002 & 0.0011 & 0.0066 & 0.0155 & 0.3397 & 0.0020 & 0.0010 & N.D. & 0.1587 & 0.4200 & 0.1388 \\
\hline Gyeongbuk & 0.0317 & 0.0007 & 0.0070 & 0.0148 & 0.0904 & 0.8618 & 0.0055 & 0.0048 & N.D. & 0.2423 & 0.7370 & 0.2437 \\
\hline Gyeongnam & 0.0115 & 0.0004 & 0.0037 & 0.0141 & 0.0251 & 0.4455 & 0.0037 & 0.0018 & N.D. & 0.1515 & 0.3827 & 0.1386 \\
\hline
\end{tabular}

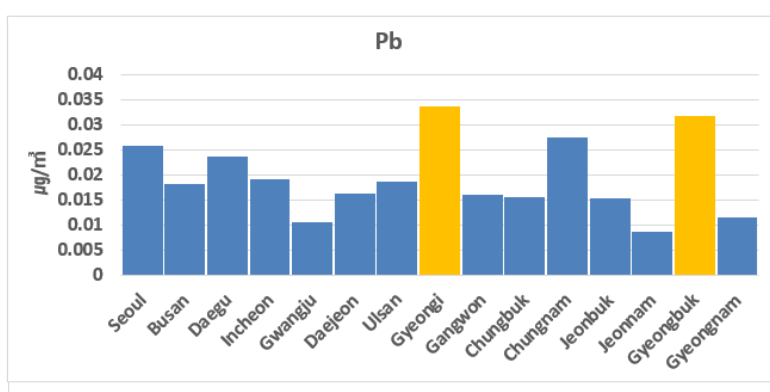

$\mathrm{Cr}$

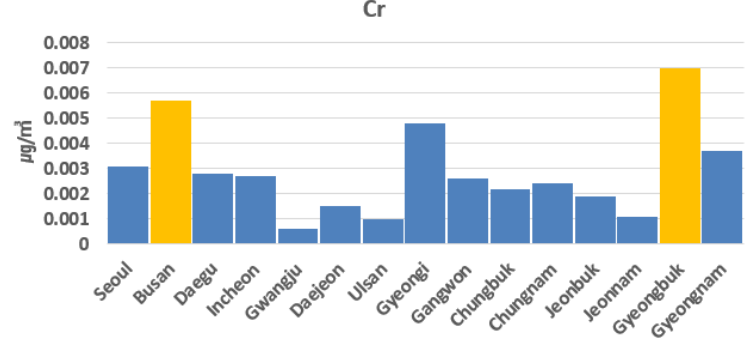

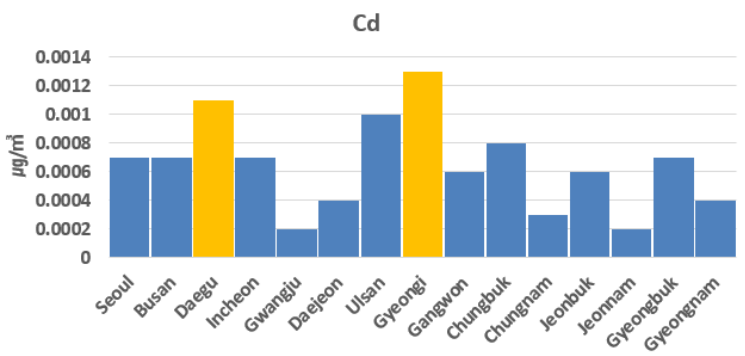

$\mathrm{Cu}$

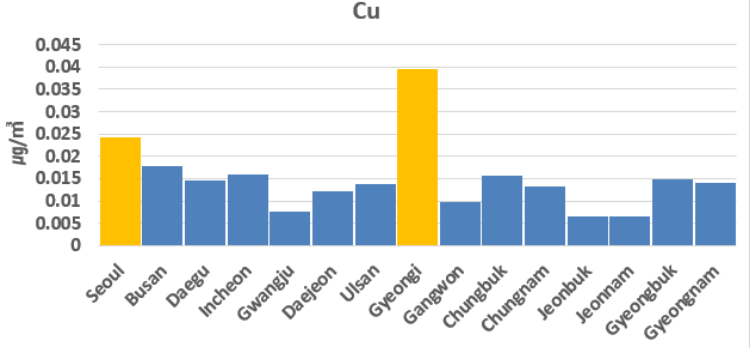

Fig. 1. Examples of heavy metal concentration comparison in Provincial and Metropolitan City governments (2019).

방법론을 사용하여 산정할 수 있다. 이 방법론에는 지구온난 화와 관련된 물질들을 고려해서 $\mathrm{kg} \mathrm{CO}$ eqv.로 표현하는 탄소 발자국과 미세먼지 형성과 관련된 물질들을 고려해서 $\mathrm{kg}$ $\mathrm{PM}_{2.5}$ eqv.로 표현하는 미세먼지 발자국 산정도 활용되어 지고 있다. ${ }^{12-14)}$ 이 방법에서 인체 독성발자국(Human Toxicity Footprint) 영향 범주에서 활용 되어지는 관련 물질들의 특성 화 계수를 활용하여 대기오염 중금속 물질 납 $(\mathrm{Pb})$, 카드뮴 $(\mathrm{Cd})$, 크롬 $(\mathrm{Cr})$, 니켈 $(\mathrm{Ni})$, 비소 $(\mathrm{As})$ 의 측정량에 각각의 특성 화 계수 $(\mathrm{CF})$ 를 곱하여 인체 독성발자국을 산정할 수 있으며 인체 독성발자국 단위는 $\mu \mathrm{g} 1,4 \mathrm{DCB}$ eqv. $/ \mathrm{m}^{3}$ 로 나타낼 수 있다(Equation (1) 참조).

$$
I_{m}(\text { midpoint impact })=\sum_{i} C F_{m i} \times m i
$$

where $\mathrm{mi}$ is the magnitude of intervention $\mathrm{i}$ (e.g., the mass of $\mathrm{Cr}$ released to air), CFmi the characterization factor that connects intervention $\mathrm{i}$ with midpoint impact category $\mathrm{m}$ (here, human carcinogenic toxicity) ${ }^{8)}$

다음의 Table 2에는 ReCiPe 2016 전과정 영향평가 방법론 에서 고려 되어지는 인체 발암성 독성 중금속 물질들의 특성 화계수를 나타내고 있다. 예를 들면, $1 \mu \mathrm{g} \mathrm{Pb}$ 는 $2.65 \mathrm{E}+01 \mu \mathrm{g}$ $1,4 \mathrm{DCB}$ eq.값을 가지며, $1 \mu \mathrm{g} \mathrm{Pb}$ 는 2.65E+01 $\mu \mathrm{g} 1,4 \mathrm{DCB}$ 
Table 2. Heavy metal emissions' characterization factors in human toxicity footprint

\begin{tabular}{ccc} 
Substance name & Unit & Midpoint ( $\mu g$ 1,4 DCB eq.) \\
$\mathrm{Pb}$ & $\mu \mathrm{g}$ & $2.65 \mathrm{E}+01$ \\
\hline $\mathrm{Cd}$ & $\mu \mathrm{g}$ & $3.10 \mathrm{E}+02$ \\
\hline $\mathrm{Cr}$ & $\mu \mathrm{g}$ & $6.67 \mathrm{E}+05$ \\
\hline $\mathrm{Ni}$ & $\mu \mathrm{g}$ & $9.06 \mathrm{E}+02$ \\
\hline $\mathrm{As}$ & $\mu \mathrm{g}$ & $2.09 \mathrm{E}+04$ \\
\hline
\end{tabular}

eq.와 상대적으로 같은 정도의 인체독성에 영향을 준다고 할 수 있다. 각 중금속 물질들의 특성화계수들을 활용하여 대기 오염 중금속 물질량을 기준으로 인체 독성발자국이 산정 되어 질 수 있다.

\section{3. 연구결과 및 토론}

\section{1. 연도별, 자자체별 대기오염중의 중금속량}

국립환경과학원 대기환경연보 $(2020)^{3)}$ 에서 구축된 자료를 바탕으로 지자체별 대기오염 중금속량 자료로 분석한 결과를 Fig. 2에 나타내었다. 2011년과 2017년부터 공개한 비소(As), 알루미늄 $(\mathrm{Al})$, 칼슘 $(\mathrm{Ca})$, 마그네슘 $(\mathrm{Mg})$ 은 경향을 볼 수 없지 만 그 외의 모든 지자체에서의 납 $(\mathrm{Pb})$, 카드뮴 $(\mathrm{Cd})$, 크롬 $(\mathrm{Cr})$, 구리 $(\mathrm{Cu})$, 망간 $(\mathrm{Mn})$, 철 $(\mathrm{Fe})$, 니켈 $(\mathrm{Ni})$ 의 농도 $\left(\mu \mathrm{g} / \mathrm{m}^{3}\right)$ 들은 쉽 게 예상할 수 있듯이 매년 계속적으로 줄어드는 경향을 볼 수 있었다. 예를 들어, 납 $(\mathrm{Pb})$ 의 경우에는 인천과 부산에서는 각각 $2,124 \%\left(0.427 \mu \mathrm{g} / \mathrm{m}^{3}\right.$ 에서 $\left.0.0192 \mu \mathrm{g} / \mathrm{m}^{3}\right)$ 와 $1,250 \%$

$\mathrm{Pb}$
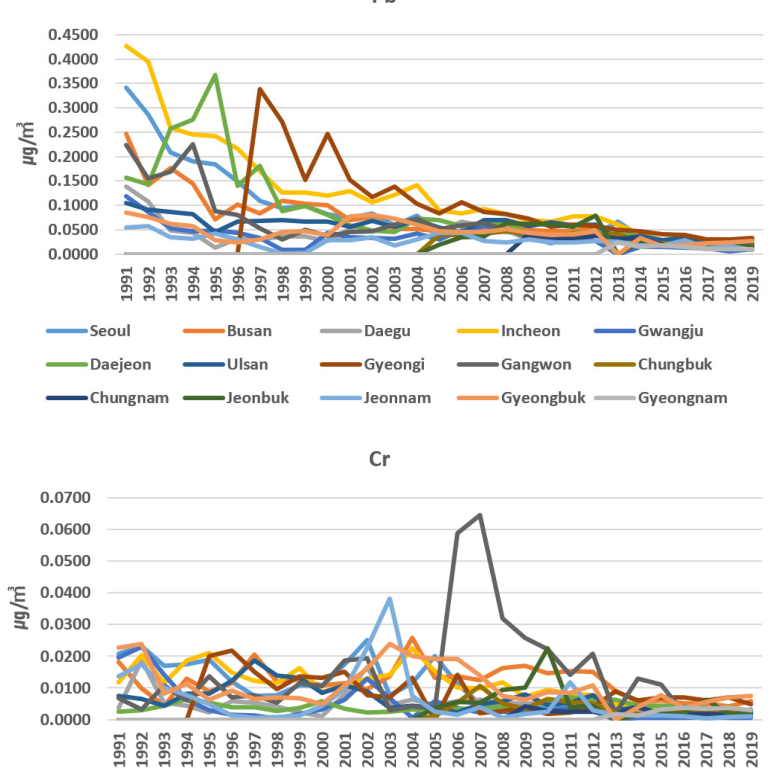

$\left(0.2471 \mu \mathrm{g} / \mathrm{m}^{3}\right.$ 에서 $\left.0.0183 \mu \mathrm{g} / \mathrm{m}^{3}\right)$ 로 상당히 많은 양이 저감 되 어진 것을 볼 수 있었다. 그리고 카드뮴 $(\mathrm{Cd})$ 의 경우에도 광주 와 인천에서 각각 $1,550 \%\left(0.0033 \mu \mathrm{g} / \mathrm{m}^{3}\right.$ 에서 $\left.0.0002 \mu \mathrm{g} / \mathrm{m}^{3}\right)$ 와 $1,071 \%\left(0.0082 \mu \mathrm{g} / \mathrm{m}^{3}\right.$ 에서 $\left.0.0007 \mu \mathrm{g} / \mathrm{m}^{3}\right)$ 로 상당히 많은 양이 저감되어진 것을 볼 수 있었다.

Fig.3에서는 서울, 부산, 광주 및 경북을 예를 들어 1991년 과 2019년 금속 및 중금속 분포 비교하여 보여주고 있다. 1991 년도는 대부분 도시에서의 금속 및 중금속은 철 $(\mathrm{Fe})$, 납 $(\mathrm{Pb})$, 구리 $(\mathrm{Cu})$, 마그네슘 $(\mathrm{Mg})$ 이 전체의 $93 \%-95 \%$ 를 차지하였으며, 2019년도에는 철 $(\mathrm{Fe})$, 칼슘 $(\mathrm{Ca})$, 알루미늄(Al)과 마그네슘 $(\mathrm{Mg})$ 이 $81 \%-86 \%$ 를 차지하고 있었으며 그 외 다른 금속 및 중금속성분들도 포함하여 다양하게 분포 되어져 있었다. 이는 1991년에는 제한적이고 중점적 산업분야들의 경제활동으로 인해서 대기 중으로 배출되는 금속 및 중금속 철 $(\mathrm{Fe})$, 납 $(\mathrm{Pb})$, 구리 $(\mathrm{Cu})$, 마그네슘 $(\mathrm{Mg})$ 들이 대부분이었다면, 2019년 최근까 지는 우리나라의 경제성장으로 인해서 다양한 산업시설, 에너 지발전 및 교통산업에서 칼슘 $(\mathrm{Ca})$ 과 철 $(\mathrm{Fe})$ 을 중심으로 알루 미늄 $(\mathrm{Al})$, 마그네슘 $(\mathrm{Mg})$, 망간 $(\mathrm{Mg})$ 많은 종류의 금속 및 중금 속들이 대기 중으로 배출되어진 것으로 판단 되어진다.

\section{2. 인체 독성발자국(Human Toxicity Footprint) 평가결과}

앞서 보여준 Equation (1)과 Table 2에서의 인체 독성 중금 속 물질들의 특성화계수를 활용하여 연도별 및 지역별 인체 독성발자국을 산정하여 Fig. 4에 나타내었다.

1991년(초기년도), 2005년(중간년도), 그리고 2019년(현재 년) 자료를 중점적으로 살펴보았다. 국내 인체 독성발자국 평

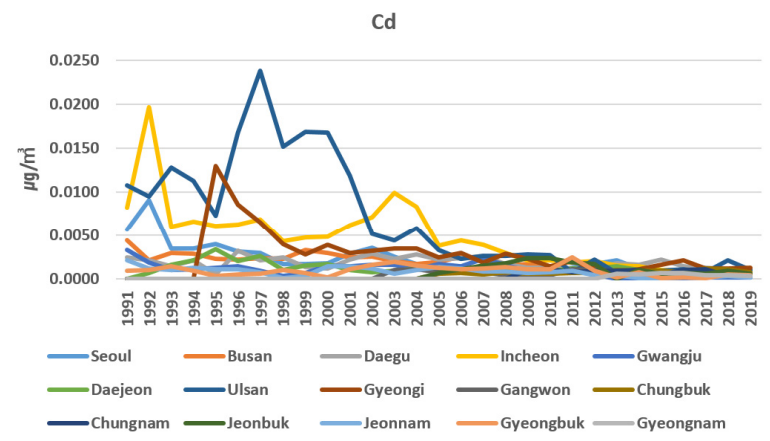

$\mathrm{Ni}$

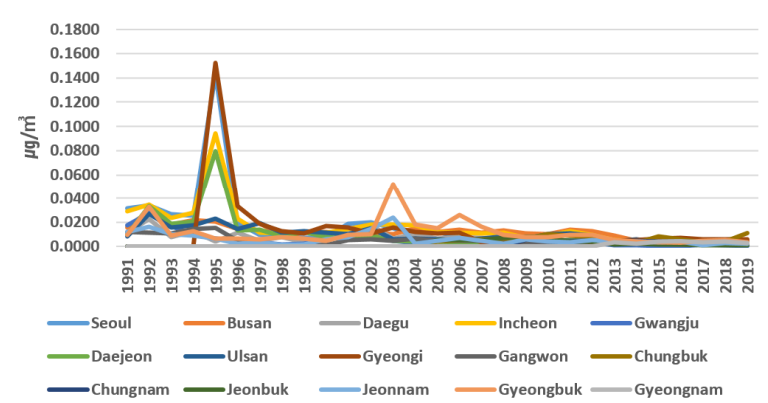

Fig. 2. Examples of heavy metal concentration in Provincial and Metropolitan City governments in each year. 

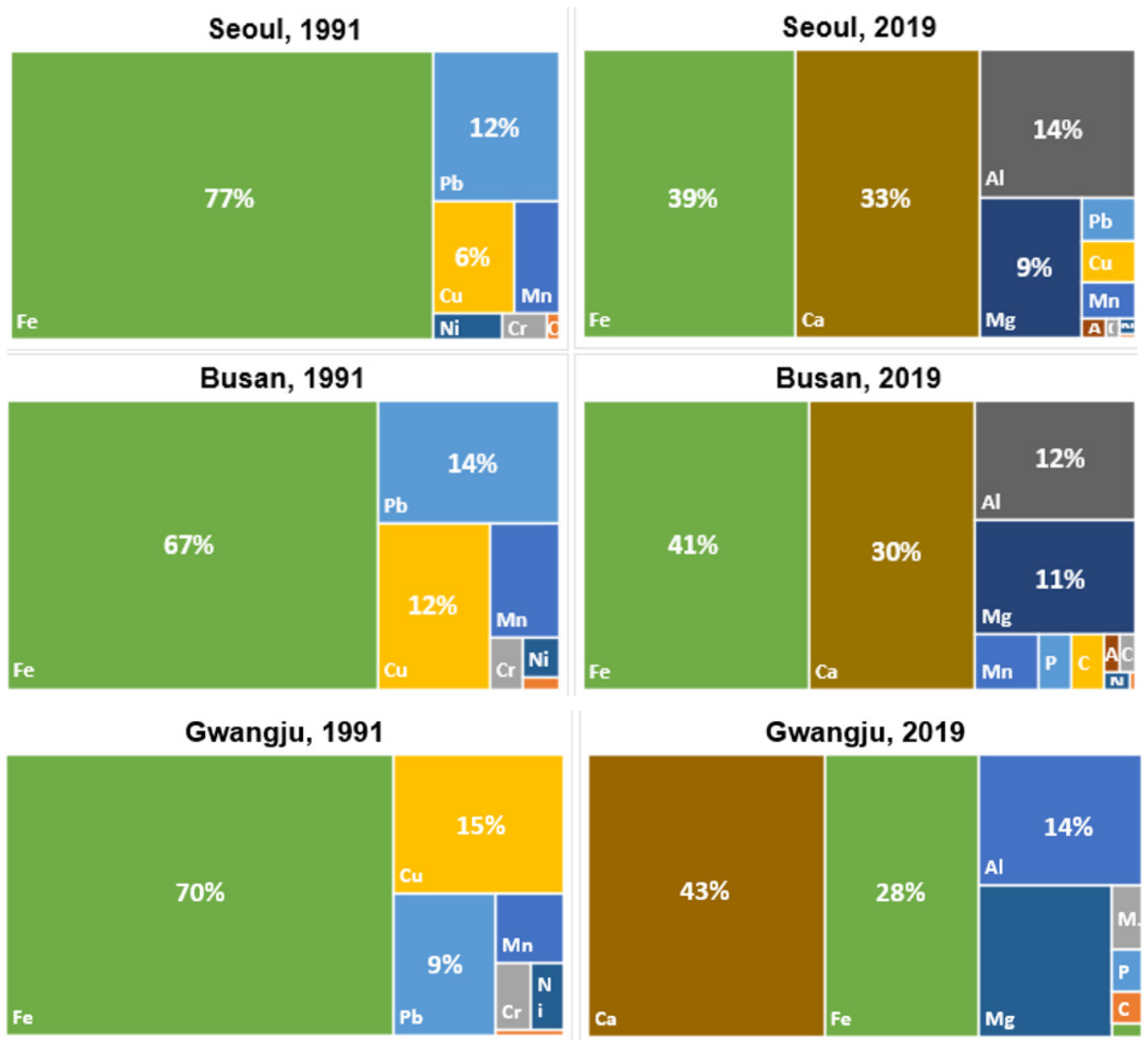

Gwangju, 2019
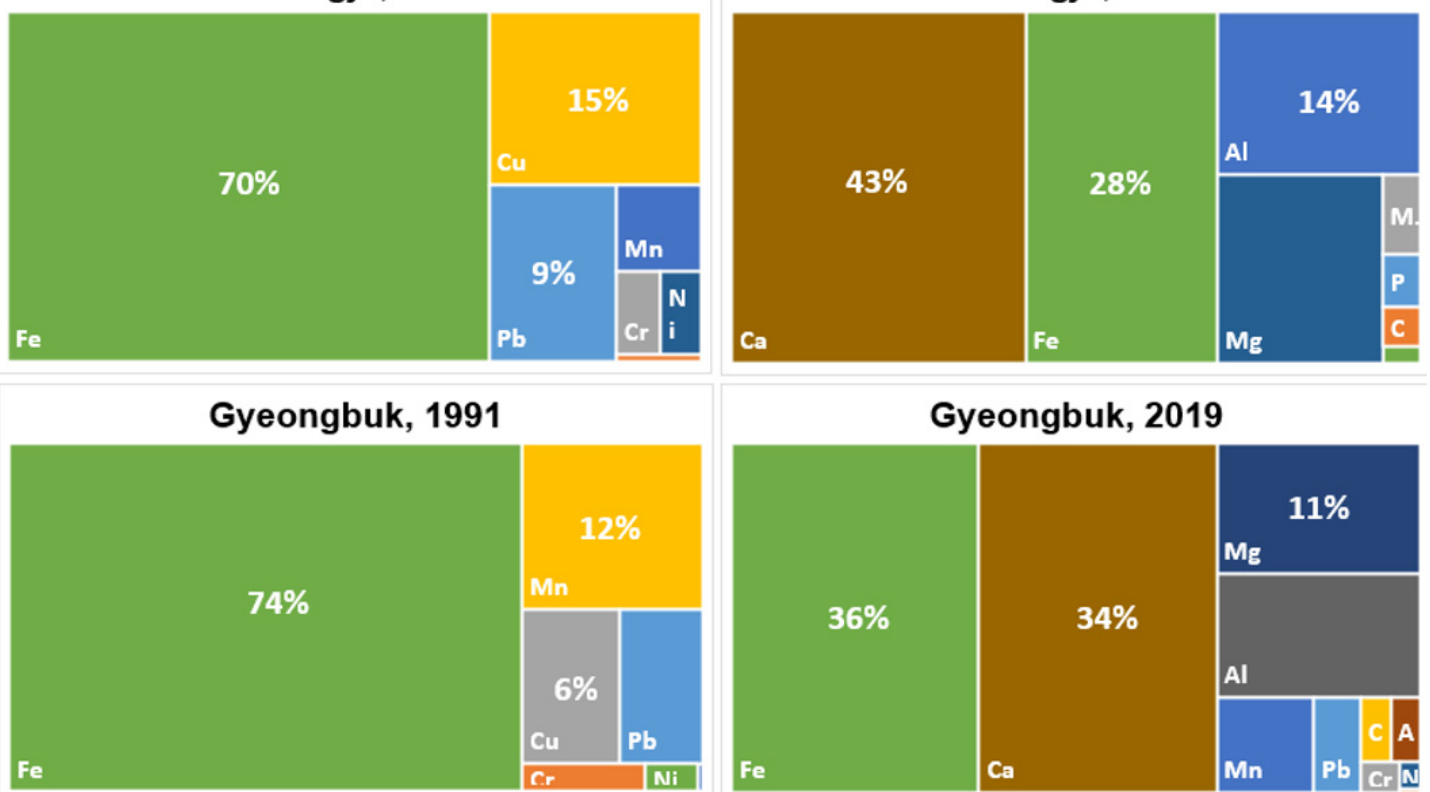

Gyeongbuk, 2019

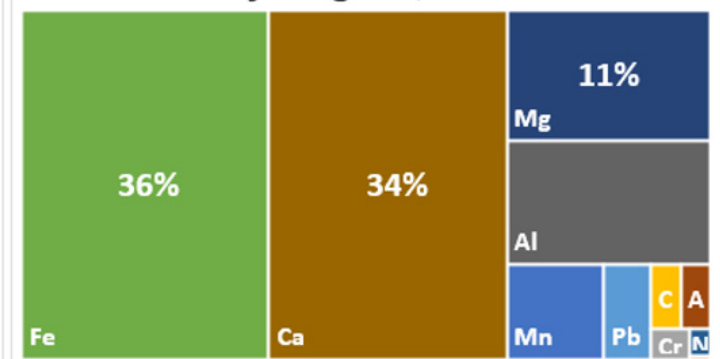

Fig. 3. Examples of each heavy metal distribution in Provincial and Metropolitan City governments in 1991 and 2019.

균결과(1995년 결과에는 자료 측정이 없었던 경기, 충북, 충 남, 전북 및 경남 제외, 2005년 결과에는 자료 측정이 없었던 충남, 경남 제외)를 보면, 1991년은 8,478 $\mu \mathrm{g} \mathrm{1,4} \mathrm{DCB}$ eqv., 2005년은 5,545 $\mu \mathrm{g}$ 1,4 DCB eqv. (1995년도에 비해서 약 53\% 저감), 그리고 2019년은 1,997 $\mu \mathrm{g} \mathrm{1,4} \mathrm{DCB} \mathrm{eqv.} \mathrm{(2005년도에}$ 비해서 약 $178 \%$ 저감)로 계속적으로 지자체별로 상당한 양의 인체 독성발자국의 저감을 가져온 것을 알 수 있다.

1991년도 결과를 좀 더 자세히 살펴보면, 경북이 $15,089 \mu \mathrm{g}$ $1,4 \mathrm{DCB}$ eqv.으로 가장 높았으며, 다음으로는 서울 13,849 $\mu \mathrm{g} 1,4 \mathrm{DCB}$ eqv., 광주 13,029 $\mu \mathrm{g} 1,4 \mathrm{DCB}$ eqv., 부산 12,165 $\mu \mathrm{g} 1,4 \mathrm{DCB}$ eqv., 전남 9,153 $\mu \mathrm{g} 1,4 \mathrm{DCB}$ eqv.순으로 높은 인체 독성발자국 값을 가졌다. 2005 년도 결과는 서울이 13,404

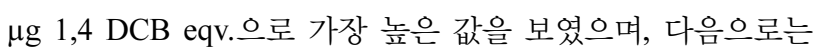
경북 $12,737 \mu \mathrm{g} 1,4 \mathrm{DCB}$ eqv., 인천 $10,283 \mu \mathrm{g} 1,4 \mathrm{DCB}$ eqv., 경기 8,777 $\mu \mathrm{g} 1,4 \mathrm{DCB}$ eqv., 부산 $8,736 \mu \mathrm{g} 1,4 \mathrm{DCB}$ eqv. 순으로 높은 인체 독성발자국 값을 가졌다. 마지막으로 2019 년도 지자체 중에서 가장 높은 인체 독성발자국 값을 가진 곳은 $5,184 \mu \mathrm{g} \mathrm{1,4} \mathrm{DCB}$ eqv.으로 경북이였다. 다음으로는 부 산 3,929 $\mu \mathrm{g} 1,4 \mathrm{DCB}$ eqv., 경기 3,305 $\mu \mathrm{g} 1,4 \mathrm{DCB}$ eqv., 서울 $2,184 \mu \mathrm{g} 1,4 \mathrm{DCB}$ eqv., 강원 2,011 $\mu \mathrm{g} 1,4 \mathrm{DCB}$ eqv. 순으로 
Human carcinogenic toxicity footprint ( $\mu$ 1,4 DCB eqv.) in 1991

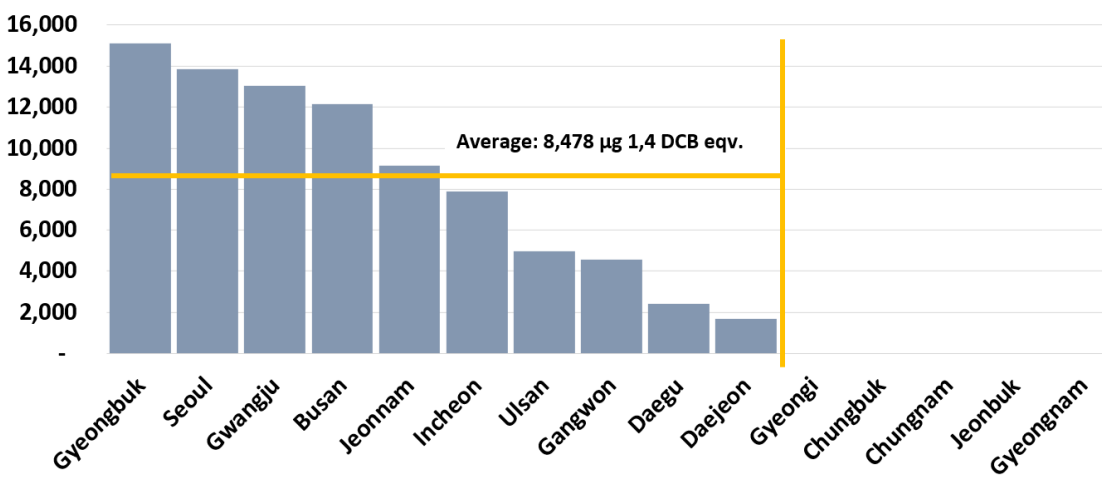

Human carcinogenic toxicity footprint ( $\mu$ g 1,4 DCB eqv.) in 2005

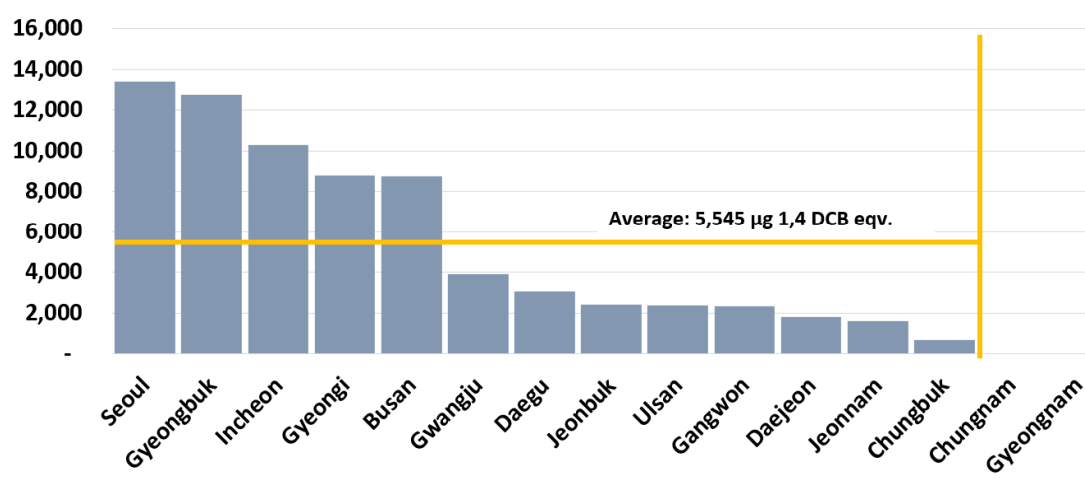

Human carcinogenic toxicity footprint ( $\mu$ g 1,4 DCB eqv.) in 2019

6,000

5,000
4,000
3,000
2,000
1,000
-

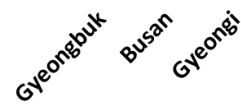

Average: $1,997 \mu \mathrm{g} 1,4 \mathrm{DCB}$ eqv.
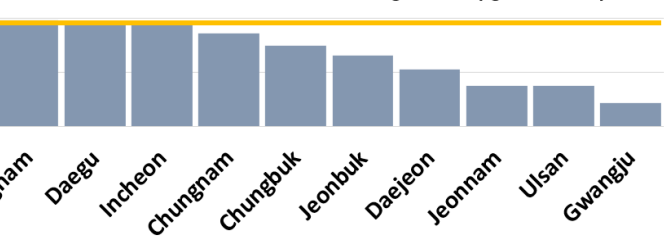

\begin{tabular}{|c|r|}
\hline \multicolumn{2}{|c|}{1991} \\
\hline Gyeongbuk & 15,089 \\
\hline Seoul & 13,849 \\
\hline Gwangju & 13,029 \\
\hline Busan & 12,165 \\
\hline Jeonnam & $\mathbf{9 , 1 5 3}$ \\
\hline Incheon & $\mathbf{7 , 9 1 3}$ \\
\hline Ulsan & 4,951 \\
\hline Gangwon & 4,537 \\
Daegu & 2,417 \\
\hline Daejeon & 1,681 \\
\hline Gyeongi & - \\
\hline Chungbuk & - \\
\hline Chungnam & - \\
\hline Jeonbuk & - \\
\hline Gyeongnam & - \\
\hline Average & 8,478 \\
\hline \multicolumn{2}{|c|}{ Unit: $\mu$ g 1,4 DCB eqv. }
\end{tabular}

\begin{tabular}{|c|r|}
\hline \multicolumn{2}{|c|}{2005} \\
\hline Seoul & 13,404 \\
\hline Gyeongbuk & 12,737 \\
\hline Incheon & 10,283 \\
\hline Gyeongi & $\mathbf{8 , 7 7 7}$ \\
\hline Busan & $\mathbf{8 , 7 3 6}$ \\
\hline Gwangju & $\mathbf{3 , 9 0 8}$ \\
\hline Daegu & $\mathbf{3 , 0 4 9}$ \\
\hline Jeonbuk & $\mathbf{2 , 4 2 4}$ \\
\hline Ulsan & $\mathbf{2 , 3 8 2}$ \\
\hline Gangwon & $\mathbf{2 , 3 1 5}$ \\
\hline Daejeon & $\mathbf{1 , 7 9 1}$ \\
\hline Jeonnam & $\mathbf{1 , 5 9 7}$ \\
\hline Chungbuk & $\mathbf{6 8 7}$ \\
\hline Chungnam & - \\
\hline Gyeongnam & - \\
\hline Average & $\mathbf{5 , 5 4 5}$ \\
\hline
\end{tabular}

Unit: $\mu g 1,4$ DCB eqv.

\begin{tabular}{|c|r|}
\hline \multicolumn{2}{|c|}{2019} \\
\hline Gyeongbuk & 5,184 \\
\hline Busan & 3,929 \\
\hline Gyeongi & 3,305 \\
\hline Seoul & 2,184 \\
\hline Gangwon & 2,011 \\
\hline Gyeongnam & 1,972 \\
\hline Daegu & 1,936 \\
\hline Incheon & 1,876 \\
\hline Chungnam & 1,725 \\
\hline Chungbuk & 1,505 \\
\hline Jeonbuk & 1,319 \\
\hline Daejeon & 1,053 \\
\hline Jeonnam & 757 \\
\hline Ulsan & 757 \\
\hline Gwangju & 441 \\
\hline Average & 1,997 \\
\hline
\end{tabular}

Fig. 4. Human carcinogenic toxicity footprint result in Provincial and Metropolitan City governments in 1991, 2005, and 2019.

높은 것으로 나타났다. 1991년부터 2019년까지 경북, 서울, 부산, 경기 지자체에서 계속적으로 평균을 넘는 인체 독성발 자국값을 가지는 것으로 나타났다.

1991년, 2005년, 2019년도 지자체별 인체 독성발자국에서 중금속 기여도 부분을 살펴보면 전체 인체 독성발자국에서 크롬 $(\mathrm{Cr})$ 의 영향이 $95 \%$ 이상으로 가장 큰 영향을 주는 것으로 나타났다. 이는 Table 2에서 볼 수 있듯이 크롬 $(\mathrm{Cr})$ 의 특성화 계수값이 다른 중금속의 특성화계수값보다 상당히 높은 값을 가지고 있기 때문(인간 독성에 상당히 높은 값을 가지고 있음) 이라고 할 수 있다. 지자체별로 인체 독성발자국 값을 줄이기 위해서는 특히, 대기 중 크롬 $(\mathrm{Cr})$ 농도를 좀 더 계속적으로
관리하여야 하며, 산업부분에서 크롬 $(\mathrm{Cr})$ 배출부분에 대한 대 책들도 필요하리라고 사료된다.

\section{4. 결 론}

최근 들어 대기 중에 존재하는 미세먼지와 함께 금속 및 중 금속 독성물질에 의한 인체 영향에 관한 문제도 심각한 문제 로 부각되고 있다. ${ }^{12)}$ 이에 본 연구에서는 국내 지자체에서의 대기 중 중금속자료를 기초로 전과정평가의 영향평가범주에 서 중금속으로 인한 인간 독성지표 산정방법을 활용하여 인체 독성발자국 개념을 정립 및 제시하고 산정 및 비교평가하였 
다. 연구 결과로는 1991년부터 2019년까지 국내 지자체에서 의 대기중 전체적인 중금속 농도는 현저히 줄어들었으며, 인 체 독성발자국 평균결과 1991년은 $8,478 \mu \mathrm{g} 1,4 \mathrm{DCB}$ eqv., 2005년은 5,545 $\mu \mathrm{g} \mathrm{1,4} \mathrm{DCB} \mathrm{eqv.,} \mathrm{그리고} \mathrm{2019년은} \mathrm{1,997} \mu \mathrm{g}$ 1,4 DCB eqv. (1991년도에 비해서 약 $325 \%$ 저감)으로 지속적 으로 지자체별로 상당한 양의 인체 독성발자국의 저감을 가져 온 것을 알 수 있다. 이는 국내 관련부처, 지자체 및 산업계 등에서 많은 노력으로 이루어진 결과라고 할 수 있다. 대기 중 중금속의 양은 우리나라 대기환경기준에 비교적 낮다고 할 수 있고, 세계보건기구 권고 기준 이하로 나타나고 있지만 체계적이며 지속적으로 관리해 나가야 할 것이다. 또한, 대기 오염 중금속 측정소 수를 늘려서 자료의 질과 대표성을 향상 시켜야 할 것으로 사료된다. 현재에는 도시지역 또는 공단 인 근 지역에서의 중금속에 의한 오염 실태를 파악하기 위해서 전국 지자체에 총 57 개소의 측정소를 운영을 하고 있지만 몇 몇 지자체에서는 (예를 들면, 전북 1 개소, 충북 2 개소, 충남 3 개소, 전남 3 개소) 적은 수의 측정소만 있기 때문에 측정자료 가 대표성을 가질 수 있도록 측정소 개수의 확대가 필요할 것으로 사료된다. ${ }^{3,16)}$ 향후에는 월별 및 계절별 분석과 동시에 지속적인 모니터링과 인체 독성발자국 산정이 필요할 것이다. 이와 더불어, 단순한 대기 중 중금속자료 구축과 공개뿐만 아 니라 지자체별로 구축된 중금속 자료를 바탕으로 각 지역별로 위치하고 있는 산업단지, 소각로, 보일러 및 산업체 활동과 함께 배출원들 간의 상관분석과 배출원인분석을 통해서 저감 또는 무배출을 위한 노력들이 필요하며, 지자체 담담기관에서 도 주기적인 점검과 확인이 필요할 것이다.

본 연구의 한계점으로 지자체별 인체 독성발자국을 산정하 기 위해서 전과정 영향평가(life cycle impact assessment) 방법 중에서 많이 활용되고 ReCiPe 2016 V.1.18방법론을 사용하여 산정하였다. 전과정 영향평가 방법에는 CML2002 (Netherlands), Eco-indicator 99 (Netherlands), EPS2000 (Sweden), TRACI (USA) 등의 다양한 방법들이 있으며, 각 영향평가 방법에서 고려하고 있는 특성화물질과 계수값이 조금씩 차이가 있기 때문에 적용하는 영향평가 방법에 따라서 결과값이 상이할 수 있다는 것이다. 앞서 사례로 나타낸 전과정 영향평가 방법 들은 유럽과 미국에서의 영향평가 방법이지만 국내에 활용하 는데는 큰 문제가 없다. 하지만 좀 더 정확한 결과값을 도출하 기 위해서는 국내 방법론(예를 들면, Korean Eco-indicator)을 지속적으로 업데이트를 해야 되며 국내 특성화계수 개발이 더욱 필요할 것으로 사료된다.

본 연구에서는 인체 독성발자국 개념을 처음으로 국내 지자 체에 적용하였으며, 이렇게 산정하여 나타낸 결과들도 지자체 의 대기 중 중금속물질의 지속적인 관리를 위해서 중요한 지 표로 고려하여 대기 중 중금속 농도의 저감 및 무배출을 위한 노력을 기울여야 할 것이다.

\section{Acknowledgment}

본 연구는 유럽환경에너지협회(EEEA)의 재정 지원에 의해 수행 되었습니다. 이에 감사드립니다.

\section{References}

1. Ministry of Environment, National PM Information center, 2017 National Air pollution Emission data, (2020).

2. World Health Organization (WHO), https://www.who.int/, (2021).

3. National Institute of Environmental Research, 2019 Air Environment Annual Report, (2020).

4. H, J. Seo, H. S. Lee, How air pollutants influence on Environmental diseases?: Focused on Seoul Metropolitan Area2, Seoul City Research, 20(3), 39-59(2019).

5. J. Y. Gong, C. S. Shim, K. C. Choi, S. Y. Gong, The Characteristics of PM2.5 Pollution and Policy Implications in Chungcheong Region, J. Korean Soc. Environ. Eng., 43(6), 407-418(2021).

6. S. W. Choi, S. W. Park, Y. W. Cha, S. I. Lee, E. C. Yoo, The Characteristics of Air Pollutants Distribution Around Industrial Complexes Using Real-Time Mobile Atmospheric Measurement System, J. Korean Soc. Environ. Eng., 43(6), 476-489(2021).

7. K. H. An, S. H. Kim, S. W. Jeong, Changes in Soil Properties after Soil Washing of Metal-contaminated Soil near the former Janghang Smelter, J. Korean Soc. Environ. Eng., 42(10), 482-492(2020).

8. K. Sung, Association between Air Pollution and Cancer Incidence by region, Ajou University, Health Graduate School, Master dissertation, (2008).

9. G. W. Lee, Exposure and risk assessment of size-related heavy metals in particulate matter, Yonsei University, Graduate School of Public Health, (2009).

10. E. J. Park, M. Kang, D. E. You, D. S. Kim, S. D. Yu, K. H. Chung, K. Park, Health Risk Assessment of Heavy Metals in Fine Particles Collected in Seoul Metropolitan Area, J. ENVIRON. TOXICOL, 20(2), 179-186(2005).

11. M. A. J. Huijbregts, Z. J. N. Steinmann, P. M. F. Elshout, G. Stam, F. Verones, M. Vieira, M. Zijp, A. Hollander, R. V. Zelm, ReCiPe2016. A harmonized life cycle impact assessment method at midpoint and endpoint level, Int. J. Life Cycle Assess, 22, 138-147(2017).

12. J. B. Kim, S. J. Jeon, J. R. Song, G. Y. Choi, A study on particulate matter footprint calculation on transportation modes, J. Korean Soc. Environ. Eng., 42(1), 1-9(2020).

13. J. B. Kim, Assessment and estimation of particulate matter formation potential and respiratory effects from air emission matters in industrial sectors and cities/regions, J. Korean Soc. Environ. Eng., 39(4), 220-228(2017).

14. J. B. Kim, J. W. Chung, S. W. Suh, H. S. Park, Comparison of direct and indirect $\mathrm{CO}_{2}$ Emission in Provincial and 
Metropolitan City governments in Korea: focused on energy consumption, J. Korean Soc. Environ. Eng., 33(12), 874-885 (2011).

15. M. H. Shah, N. Shaheen, M. Jaffar, A. Khalique, S. R. Tariq, S. Manzoor, Spatial variations in selected metal contents and particle size distribution in an urban and rural atmosphere of Islamabad, Pakistan, Journal of Environmental Management, 78(2), 128-137(2006).

16. J. S. Chae, K. R. Park, J. M. Jeon, J. Y. Lee, Characteristics of Heavy Metal Pollution in the Atmosphere in Residential Area near the Gwangyang Industrial Complex, Journal of the Korean Society of Urban Environment, 20(1), 25-35(2020).

\section{Declaration of Competing Interest}

The author declares that they have no known competing financial interests or personal relationships that could have appeared to influence the work reported in this paper.

\section{Authors and Contribution Statement}

\section{Junbeum Kim}

Associate Professor, University of Technology of Troyes, ORCID (1) 0000-0003-0665-7989: Data collection, Data analysis, Writing. 